\title{
Detection of Cyclospora in captive chimpanzees and macaques by a quantitative PCR-based mutation scanning approach
}

Marianna Marangi ${ }^{1,2}$, Anson V Koehler ${ }^{2}$, Sergio A Zanzani ${ }^{3}$, Maria T Manfredi ${ }^{3}$, Emanuele Brianti ${ }^{4}$, Annunziata Giangaspero ${ }^{1^{*}}$ and Robin B Gasser ${ }^{2^{*}}$

\begin{abstract}
Background: Cyclospora is a protistan parasite that causes enteritis in several species of animals including humans. The aim of this study was to investigate the presence of Cyclospora in captive non-human primates.

Methods: A total of 119 faecal samples from Pan troglodytes, Macaca sylvanus, Cercopithecus cephus, Erythrocebus patas, Chlorocebus aethiops and Macaca fascicularis from a wildlife animal rescue center as well as from Macaca fascicularis from an experimental primate research center were tested for the presence of Cyclospora by quantitative real-time PCR ( $(\mathrm{PCCR})$ and single-strand conformation polymorphism (SSCP) analysis.

Results: Cyclospora was detected in three Pan troglodytes (13.6\%) and nine (9.3\%) Macaca fascicularis.

Conclusions: The present study represents the first record of Cyclospora in captive primates in Europe, suggesting the presence of Cyclospora cayetanensis, which is transmissible to humans.
\end{abstract}

Keywords: Cyclospora, aPCR, Mutation scanning-based sequencing, Non-human primates, Zoonosis

\section{Background}

Enteritis caused by protistan parasites is a principal cause of substantial morbidity in humans, often resulting in mortality in under-privileged communities [1]. Protozoa belonging to the genus Cyclospora (Apicomplexa: Eimeriidae) are obligate, intracellular parasites that infect the epithelium of the intestines or bile ducts of a variety of hosts, mostly vertebrates [2]. Nineteen species of Cyclospora have been described in millipedes, reptiles, insectivores, rodents, and human and non-human primates [2]. In humans, Cyclospora was first identified in Papua New Guinea in the late 1970s [3] and then named Cyclospora cayetanensis [4,5] in the early 1990s. Cyclospora cayetanensis has since been recognized as an important cause of endemic or epidemic diarrhoeal illness in children and immuno-compromised or -suppressed individuals worldwide [6]. Human cyclosporosis is endemic in developing countries, but also in

\footnotetext{
* Correspondence: annunziata.giangaspero@unifg.it; robinbg@unimelb.edu.au 'Department of Science of Agriculture, Food and Environment, University of Foggia, Foggia, Italy

${ }^{2}$ Faculty of Veterinary and Agricultural Sciences, The University of Melbourne, Victoria, Australia

Full list of author information is available at the end of the article
}

industrialized settings, mainly in people with no history of foreign travel [7] and sometimes implicated in communitywide outbreaks of diarrhoeal illness [7].

Cyclospora species appear to be underestimated as infectious agents, and very little is known about their epidemiology (including host and geographical ranges) and pathogenicity $[7,8]$. Infections are transmitted via the faecal-oral route through contaminated environmental water, food or soil, although oocysts need to sporulate outside of the mammalian host (from 7-15 days) to be infective [9].

Investigations of outbreaks and case-control studies have shown that people with cyclosporosis had contact with animals, suggesting a zoonotic role of $C$. cayetanensis. Cyclospora oocysts, morphologically resembling C. cayetanensis, have been detected in chickens, ducks, cattle, mice, rats and dogs [10-14], whereas morphologically and molecularly characterized $C$. cayetanensis have been identified in dogs, domestic birds and in monkeys (Mulatta mulatta) [10]. This evidence supports the possible zoonotic nature of $C$. cayetanensis, although whether animals from which 
this parasite have been isolated are natural hosts is still unknown.

Investigations of Cyclospora of animals, particularly those with a close genetic relationship with humans, have important implications for better understanding the epidemiology and host range of members of this genus. PCR-based tools employing various nuclear (e.g., ribosomal and heat shock protein) gene markers have been utilized to detect and/or identify Cyclospora spp. [15]. In the present study, a quantitative PCR ( $q$ PCR), combined with single-strand conformation polymorphism (SSCP)-based sequencing analysis, was used for the detection and genetic characterization of Cyclospora from various species of captive primates using the second internal transcribed spacer (ITS-2) of nuclear ribosomal DNA as a marker.

\section{Methods}

\section{Samples and isolation of genomic DNA}

Fresh faecal samples from 119 captive, non-human primate individuals were collected in Italy; 22 samples were from Pan troglodytes, Macaca sylvanus, Cercopithecus cephus, Erythrocebus patas, Chlorocebus aethiops and Macaca fascicularis from a Wildlife Animal Rescue Center (WARC; 2008) and 97 from M. fascicularis from an Experimental Primate Research Center (EPRS; 2011-2012) (Table 1). Primates were kept in enclosures strictly according to the Guidelines for the Care and Use of Laboratory Animals of the Ministry of Health, Italy. None of the animals studied showed clinical signs, such as diarrhoea, at the time of sampling. Faecal samples (packed in individual plastic bags) were sent frozen to the Parasitology Laboratory, Department of Agriculture Science, Food and Environment, University of Foggia, Italy, where they were stored at $-80^{\circ} \mathrm{C}$. Subsequently, samples were thawed, and genomic DNAs were isolated from individual faecal samples using the Qiagen stool kit (Macherey-Nagel, Germany), according to the manufacturer's instructions. DNA was eluted in $50 \mu \mathrm{l}$ of $\mathrm{H}_{2} 0$, quantified using a Qubit 2.0 fluorometer and stored at $-20^{\circ} \mathrm{C}$. The individual genomic DNA samples contained 0.2 to $100 \mathrm{ng}$ per $\mu$ l.

\section{Quantitative $q \mathrm{PCR}$ and melting curve analysis}

The $q \mathrm{PCR}$ assay and melting curve analysis were performed in a CFX-96 Real Time Instrument (BioRad, Italy) [16]. Briefly, PCR was carried out in a final volume of $20 \mu$ l, utilizing SsoFast $^{\mathrm{Tm}}$ EvaGreen ${ }^{\circ}$ Supermix (cat. no. 172-5201; Bio-Rad, Italy) and $0.5 \mu \mathrm{M}$ of each primer CCITS2-F (forward: 5'-GCAGTCACAGGAGGCATATATCC-3') and CCITS2-R (reverse: 5'-ATGAGAGACCTCACAGCCAAAC-3') to a region (116 bp) within ITS-2 of C. cayetanensis (cf. [17]). Genomic DNA (50 to $100 \mathrm{ng}$ ), cloned ITS-2 (0.5 pg; reference, positive-control) DNA or water (negative control) in $5 \mu \mathrm{l}$ were added to the reaction. Cycling conditions were: initial denaturation at $98^{\circ} \mathrm{C}$ for $2 \mathrm{~min}$, followed by 35 cycles at $98^{\circ} \mathrm{C}$ for $5 \mathrm{~s}$, and $59^{\circ} \mathrm{C}$ for $15 \mathrm{~s}$. Fluorescence data were collected at the end of each cycle as a single acquisition. Melting curve analysis was performed at the end of each PCR run $\left(70^{\circ} \mathrm{C}\right.$ to $95^{\circ} \mathrm{C}$ at $\left.0.5^{\circ} \mathrm{C} / 5 \mathrm{~s}\right)$. Each sample was analyzed in duplicate, and the amplification cycle threshold $(C t)$ and melting temperature $(T m)$ values were calculated. The diagnostic Tm peak for Cyclospora was $84.5^{\circ} \mathrm{C}$. The criteria used to define a test-positive sample were: (a) a detectable amplification curve, (b) a Tm value of $\pm 0.5^{\circ} \mathrm{C}$ with reference to the $T m$ value of plasmid control, and (c) a dF/dT fluorescence value of $>2$.

Raw data were normalized by applying curve-scaling to a line of best fit, so that the highest fluorescence value was 100 and the lowest was zero (standard normalized melt curve). Then, the curves were differentiated, and a composite median curve was constructed using the median fluorescence values for each sample. The melting traces for each sample were subtracted from this composite median curve to draw a residual plot (difference graph). The number of DNA copies per $\mu \mathrm{l}$ was calculated by relating the $C t$ mean value of each sample to a standard curve for the plasmid control, and the number of oocysts calculated, assuming that an oocyst contains 15 copies of rDNA [18].

\section{qPCR performance}

The analytical sensitivity of the assay was estimated using 10 -fold serial dilutions (from $10^{10}$ to 10 copies/ $\mu \mathrm{l}$ ) of the (cloned) reference (positive) control, which were each subjected (in triplicate) to $q \mathrm{PCR}$ and subsequent melting curve analysis, and the mean value of the threshold cycle $(C t)$ was plotted against the logarithm of DNA copies per $\mu \mathrm{l}$. The standard curve was produced by a linear regression of the plotted points and the range of linearity and the lowest detectable amount of DNA were estimated. PCR efficiency $(E)$ was calculated according to the equation: $E=10^{-1}$ slope -1 [19]. $E$ of between 90 and $110 \%$ and a correlation $\left(R^{2}\right)$ of $<1$ value were considered acceptable. To determine repeatability, three standard points of (cloned) reference (positive) control $\left(10^{7}, 10^{5}\right.$ and 10 copies/ $\mu \mathrm{l}$ ) were tested in triplicate three times in the same experiment and the $C t$ mean values were recorded. The same standards were tested once a day for three more days to determine reproducibility. To analyze the reproducibility and repeatability, both intra- and interassay coefficients of variation $(C V)$ were assessed. $C V$ mean values were calculated following the formula: $\mathrm{CV}=\sigma(C t) / \mu(C t)$.

\section{Single-strand conformation polymorphism (SSCP) analysis} and sequencing

All amplicons were subjected to single-strand conformation polymorphism (SSCP) analysis using protocol B 
Table 1 Number and species of investigated non-human primates and samples test-positive for Cyclospora by both qPCR and SSCP analysis

\begin{tabular}{|c|c|c|c|c|c|c|c|}
\hline \multirow{2}{*}{$\begin{array}{l}\text { Collection } \\
\text { sites }\end{array}$} & \multirow{2}{*}{$\begin{array}{l}\text { Animal } \\
\text { number }\end{array}$} & \multirow[t]{2}{*}{ Species } & \multirow[t]{2}{*}{ Common name } & \multirow[t]{2}{*}{$\operatorname{Sex}^{\mathrm{a})}$} & \multicolumn{2}{|c|}{ Cyclospora } & \multirow{2}{*}{$\begin{array}{l}\text { No. of } \\
\text { oocysts }^{b}\end{array}$} \\
\hline & & & & & $\overline{q P C R}$ & SSCP & \\
\hline \multirow[t]{12}{*}{$\overline{\text { WARC }}$} & 1 & Pan troglodytes & Chimpanzee & $f$ & + & + & 498 \\
\hline & 2 & Pan troglodytes & Chimpanzee & $\mathrm{m}$ & - & - & 0 \\
\hline & 3 & Pan troglodytes & Chimpanzee & $\mathrm{m}$ & + & + & 420 \\
\hline & $4-6$ & Pan troglodytes & Chimpanzee & $\mathrm{m}$ & - & - & 0 \\
\hline & 7 & Pan troglodytes & Chimpanzee & $f$ & + & + & 482 \\
\hline & $8-12$ & Pan troglodytes & Chimpanzee & $f$ & - & - & 0 \\
\hline & $13-15$ & Pan troglodytes & Chimpanzee & $f$ & - & - & 0 \\
\hline & $16-18$ & Macaca sylvanus & Barbary macaque & $\mathrm{m}$ & - & - & 0 \\
\hline & 19 & Chlorocebus aethiops & Green monkey & $\mathrm{m}$ & - & - & 0 \\
\hline & 20 & Macaca fascicularis & Cynomolgus monkey & $f$ & - & - & 0 \\
\hline & 21 & Erythrocebus patas & Patas monkey & $\mathrm{m}$ & - & - & 0 \\
\hline & 22 & Cercopithecus cephus & Moustached monkey & $\mathrm{m}$ & - & - & 0 \\
\hline \multirow[t]{11}{*}{ EPRC } & 1 & Macaca fascicularis & Cynomolgus monkey & $f$ & + & + & 314 \\
\hline & 2 & Macaca fascicularis & Cynomolgus monkey & $f$ & + & + & 470 \\
\hline & 3 & Macaca fascicularis & Cynomolgus monkey & $f$ & + & + & 439 \\
\hline & 4 & Macaca fascicularis & Cynomolgus monkey & $f$ & + & + & 89 \\
\hline & $5-55$ & Macaca fascicularis & Cynomolgus monkey & $f, m$ & - & - & 0 \\
\hline & 56 & Macaca fascicularis & Cynomolgus monkey & $\mathrm{m}$ & + & + & 285 \\
\hline & 57 & Macaca fascicularis & Cynomolgus monkey & $\mathrm{m}$ & + & + & 196 \\
\hline & 58 & Macaca fascicularis & Cynomolgus monkey & $\mathrm{m}$ & + & + & 162 \\
\hline & 59 & Macaca fascicularis & Cynomolgus monkey & $\mathrm{m}$ & + & + & 232 \\
\hline & 60 & Macaca fascicularis & Cynomolgus monkey & $\mathrm{m}$ & + & + & 80 \\
\hline & $61-97$ & Macaca fascicularis & Cynomolgus monkey & $\mathrm{m}$ & - & - & 0 \\
\hline
\end{tabular}

WARC: Wildlife Animal Rescue Center; EPRC: Experimental Primate Research Center.

a) $f=$ female; $m=$ male

b) Per gram of feaces.

[20]. Amplicons representing distinct banding profiles were selected and treated with exonuclease I and shrimp alkaline phosphatase (Fermentas), according to the manufacturer's instructions, and then subjected to direct, automated sequencing (BigDye Terminator v.3.1 chemistry, Applied Biosystems, USA) using the primer CCITS2-R. The quality of each sequence was assessed based on the corresponding electropherogram using the program BioEdit, and the sequences determined were compared with known reference sequences using the Basic Local Alignment Search Tool (BLAST; http://www.ncbi.nlm.nih.gov/ BLAST).

\section{Results and discussion}

Upon assessing assay performance, we established that intra-assay $C V$ values for the $10^{7}, 10^{5}$ and 10 standard points were $1.8 \%, 1.5 \%$, and $1.2 \%$, and inter-assay $C V$ values for the $10^{7}$, respectively $10^{5}$ and 10 standard points were $0.80 \%, 0.60 \%$, and $0.93 \%$, respectively. The range of linearity was acceptable from $10^{10}$ to 10 copies/ $\mu$ l, with an amplification efficiency $(E)$ of $93.6 \%$ and a slope of $-3,486\left(R^{2}=0.995\right)$. The $q$ PCR was then applied to the test samples.

Twelve of 119 (10.1\%) faecal samples were $q$ PCR testpositive for Cyclospora, including 3 (13.6\%) chimpanzees (Pan troglodytes) from 22 primates from the WARC and 9 (9.3\%) from 97 cynomolgus monkeys (syn. crab-eating macaque) (Macaca fascicularis) from the EPRC (Table 1). The numbers of Cyclospora oocysts in test-positive samples were predicted to range from 80 to 498 per gram of faeces (Table 1). All 12 Cyclospora ITS-2 amplicons produced in $q \mathrm{PCR}$ were subjected to SSCP analysis, and one profile was displayed for both non-human primate species. The sequence representing all 12 amplicons was identical to the reference sequence with GenBank accession no. AF301386.

Although the sequence of these amplicons was consistent with those determined for $C$. cayetanensis, some caution is needed in assigning species status, for the following reasons: $(i)$ it is not yet known whether ITS-2 
provides unequivocal specific identification of Cyclospora and (ii) we did not detect oocysts of Cyclospora for morphological identification/description. Therefore, although Cyclospora DNA was amplified using primers designed to ITS-2 of C. cayetanensis [17], the magnitude of sequence variation within individual, recognized species of Cyclospora as well as the levels of difference among recognised species of Cyclospora have not yet been rigorously assessed.

Although various non-human primates have been reported to harbour unique Cyclospora species, such as Cyclospora cercopitheci n. sp. in green monkeys, C. colobi n. sp. in colobus monkeys, and C. papionis sp. n. in baboons [21-23], the finding of Cyclospora-like oocysts in chimpanzees (P. troglodytes), baboons (Papio cynochephalus) [11] and in drills (Mandrillus leucophaeus) [14] raises the vexed question as to the specific identity of these parasites and whether they are transmissible to humans or not.

Given that attempts to infect different animal species (chickens, ducks, mice, gerbils, hamsters, rabbits, rats, sand rats, ferrets, pigs, dogs, monkeys and baboons) with C. cayetanensis have been unsuccessful [24], it is possible that Cyclospora species are predominantly hostspecific, like Eimeria [25]; thus, further investigation is warranted in this regard. The identification of Cyclospora in a chimpanzee supports the previous detection of this parasite in this primate species [11]; if C. cayetanesis is confirmed, the role of M. fascicularis as a reservoir of this protozoan might support its molecular detection in a related species of macaque (i.e., Macaca mulatta) in Nepal [10].

While coprophagia is a likely mode of transmission of parasitic infections in captive primates [26], the animals studied here might have become infected by Cyclospora through water, soil or food (mostly fruit). Indeed, contaminated tap water and fresh produce (fruits and leafy vegetables) [27-29] are recognized as key sources of cyclosporosis outbreaks in humans [7,30], while the role of contaminated soil has only been suspected $[8,29]$ but not yet proven.

It is possible that cynomolgus monkeys from the EPRS premises had been infected by Cyclospora upon arrival from China, where Cyclospora-like organisms have been detected recently in golden snub-nosed monkeys (Rhinopithecus roxellanae) from the Breeding Research Center in Shaanxi province, China [23], and where cyclosporosis in humans has often been reported [31-33]. Regarding chimpanzees from WARC, it is possible that the contamination might have been acquired locally, since the animals were not recently moved or imported from other areas. In Italy, humans have been found to harbour C. cayetanensis [34-36], and this parasite has also been isolated from stored tap water [37].

\section{Conclusions}

Although the possible zoonotic role of Cyclospora detected herein cannot be confirmed, the high number of Cyclospora oocysts shed in faeces might be a public health concern, considering their resilience in the environment and to routine chemicals used to disinfect water $[7,38]$, which might facilitate their dissemination via water and food and the environment to humans and/or other animals. Understanding the host and distributional ranges of Cyclospora species and transmission thereof should have important implications for preventing and controlling cyclosporosis. Whether the nonhuman primates studied here serve as natural reservoirs for C. cayetanensis remains unclear, and future investigations are warranted to confirm the specific status of Cyclospora detected in the present study.

\section{Abbreviations}

qPCR: quantitative real-time PCR; SSCP: Single-strand conformation polymorphism.

\section{Competing interests}

The authors declare that they have no competing interest.

\section{Authors' contributions}

MM and AVK undertook molecular work; ASZ, MTM and EB undertook collections; RBG and AG designed the study and wrote the paper. All authors read and approved the final version of the manuscript.

\section{Acknowledgements}

The authors thank Drs. Raffaella Terlizzi and Tiziana Caradonna for technical assistance. RBG's research is funded through the Australian Research Council (ARC), Melbourne Water Corporation, and the National Health and Medical Research Council (NHMRC) of Australia; it is also supported by a Victorian Life Sciences Computation Initiative (VLSCI) grant number VR0007 on its Peak Computing Facility at the University of Melbourne, an initiative of the Victorian Government.

\section{Author details}

${ }^{1}$ Department of Science of Agriculture, Food and Environment, University of Foggia, Foggia, Italy. ${ }^{2}$ Faculty of Veterinary and Agricultural Sciences, The University of Melbourne, Victoria, Australia. ${ }^{3}$ Department of Animal Pathology, Hygiene and Public Health, University of Milan, Milan, Italy. ${ }^{4}$ Department of Veterinary Sciences, University of Messina, Messina, Italy.

Received: 22 April 2015 Accepted: 23 April 2015

Published online: 15 May 2015

\section{References}

1. Fletcher M, McLaws M, Ellis J. Prevalence of gastrointestinal pathogens in developed and developing countries: systematic review and meta-analysis. J Public Health Res. 2013;2:e9.

2. Lainson R. The genus Cyclospora (Apicomplexa: Eimeriidae), with a description of Cyclospora schneideri n. sp. In the snake Anilius scytale scytale (Aniliidae) from Amazonian Brazil-a review. Mem Inst Oswaldo Cruz. 2005;100:103-10.

3. Ashford RW. Occurrence of an undescribed coccidian in man in Papua New Guinea. Ann Trop Med Parasitol. 1979;73:497-500.

4. Ortega YR, Sterling CR, Gilman RH, Cama VA, Diaz F. Cyclospora species-a new protozoan pathogen of humans. N Engl J Med. 1993;328:1308-12.

5. Ortega YR, Gilman RH, Sterling CR. A new coccidian parasite (Apicomplexa: Eimeriidae) from humans. J Parasitol. 1994;80:625-9.

6. Shields JM, Olson BH. Cyclospora cayetanensis: a review of an emerging parasitic coccidian. Int J Parasitol. 2003;33:371-91.

7. Ortega YR, Sanchez R. Update on Cyclospora cayetanensis, a food-borne and waterborne parasite. Clin Microbiol Rev. 2010;23:218-34. 
8. Chacin-Bonilla L. Importance of contact with soil in the transmission of cyclosporosis. Acta Trop. 2010;115:181-93.

9. Mansfield LS, Gajadhar AA. Cyclospora cayetanensis, a food- and waterborne coccidian parasite. Vet Parasitol. 2004;126:73-90.

10. Chu DM, Sherchand JB, Cross JH, Orlandi PA. Detection of Cyclospora cayetanensis in animal fecal isolates from Nepal using an FTA filter-base polymerase chain reaction method. Am J Trop Med Hyg. 2004;71:373-9.

11. Smith HV, Paton CA, Girdwood RW, Mtambo MM. Cyclospora in non-human primates in Gombe, Tanzania. Vet Rec. 1996;138:528.

12. Lopez FA, Manglicmot J, Schmidt TM, Yeh C, Smith HV, Relman DA. Molecular characterization of Cyclospora-like organisms from baboons. J Infect Dis. 1999;179:670-6.

13. Perez Cordon G, Hitos Prados A, Romero D, Sánchez Moreno M, Pontes A. Intestinal parasitism in the animals of the zoological garden 'Peña Escrita' (Almuñecar, Spain). Vet Parasitol. 2008;156:302-9.

14. Eberhard ML, Owens JR, Bishop HS, de Almeida ME, da Silva AJ. Cyclospora spp. in drills, Bioko Island, Equatorial Guinea. Emerg Infect Dis. 2014;20:510-1.

15. Verweij JJ. Application of PCR-based methods for diagnosis of intestinal parasitic infections in the clinical laboratory. Parasitology. 2014;141:1863-72.

16. Aksoy U, Marangi M, Papini R, Ozkoc S, Bayram Delibas S, Giangaspero A. Detection of Toxoplasma gondii and Cyclospora cayetanensis in Mytilus galloprovincialis from Izmir Province coast (Turkey) by real time PCR/HighResolution Melting analysis (HRM). Food Microbiol. 2014;44:128-35.

17. Lalonde LF, Gajadhar AA. Highly sensitive and specific PCR assay for reliable detection of Cyclospora cayetanensis oocysts. Appl Environ Microbiol. 2008;74:4354-8.

18. Varma M, Hester JD, Schaefer FW. Ware 3rd, MW, lindquist HD: Detection of Cyclospora cayetanensis using a quantitative real-time PCR assay. J Microbiol Methods. 2003;53:27-36.

19. Rasmussen R. Rapid cycle real time PCR: methods and applications. Germany: Springer, Heidelberg; 2001. p. 21-34

20. Gasser RB, Hu M, Chilton NB, Campbell BE, Jex AR, Otranto D, et al. Single-strand conformation polymorphism (SSCP) for the analysis of genetic variation. Nat Protoc. 2006;1:3121-228.

21. Eberhard ML, DaSilva AJ, Lilley BG, Pieniazek NJ. Morphologic and molecular characterization of new Cyclospora species from Ethiopian monkeys: C. cercopitheci n. sp., C. colobi n. sp., and C. papionis n. sp. Emerg Infect Dis. 1999;5:651-8.

22. Eberhard ML, Njenga MN, DaSilva AJ, Owino D, Nace EK, Won KY. A survey for Cyclospora spp. in Kenyan primates, with some notes on its biology. J Parasitol. 2001;87:1394-7.

23. Zhao GH, Cong MM, Bian QQ, Chen WY, Wang RJ, Qi M, et al. Molecular characterization of Cyclospora-like organisms from golden snub-nosed monkeys in Qinling Mountain in Shaanxi province, northwestern China. PLoS One. 2013;8:e58216.

24. Eberhard ML, Ortega YR, Hanes DE, Nace EK, Do RQ, Robl MG, et al. Attempts to establish experimental Cyclospora cayetanensis infection in laboratory animals. J Parasitol. 2000;86:577-2.

25. Relman DA, Schmidt TM, Gajadhar A, Sogin M, Cross J, Yoder K, et al. Molecular phylogenetic analysis of Cyclospora, the human intestinal pathogen, suggests that it is closely related to Eimeria species. J Infect Dis. 1996;173:440-5.

26. Nishikawa M, Mochida K. Coprophagy-related interspecific nocturnal interactions between Japanese macaques (Macaca fuscata yakui) and sika deer (Cervus nippon yakushimae). Primates. 2010;51:95-9.

27. Herwaldt BL, Ackers ML. An outbreak in 1996 of cyclosporiasis associated with imported raspberries. The Cyclospora Working Group. N Engl J Med. 1997;336:1548-56.

28. Herwaldt BL, Beach MJ. The return of Cyclospora in 1997: another outbreak of cyclosporiasis in North America associated with imported raspberries. The Cyclospora Working Group. Ann Intern Med. 1999;130:210-20.

29. Koumans EH, Katz DJ, Malecki JM, Kumar S, Wahlquist SP, Arrowood MJ, et al. An outbreak of cyclosporiasis in Florida in 1995: a harbinger of multistate outbreaks in 1996 and 1997. Am J Trop Med Hyg. 1998;59:235-42.

30. Hall RL, Jones JL, Hurd S, Smith G, Mahon BE, Herwaldt BL. Populationbased active surveillance for Cyclospora infection-United States, foodborne diseases active surveillance network (foodnet), 1997-2009. Clin Infect Dis. 2012;54 Suppl 5:S411-7.

31. Wang KX, Li CP, Wang J, Tian Y. Cyclospora cayetanensis in Anhui, China. World J Gastroenterol. 2002:8:1144-8.
32. Xing WL, Wu KW, Ling XY, Huang HC, Liu QZ, Zheng XY, et al. Prevalence survey on Cyclospora cayetanensis in diarrhea cases in Wenzhou. Chin J Parasit Dis. 2002;15:320-1 (in Chinese).

33. Zhou Y, Lv B, Wang Q, Wang R, Jian F. Prevalence and molecular characterization of Cyclospora cayetanensis, Henan, China. Emerg Infect Dis. 2011;17:1887-90.

34. Scaglia M, Gatti S, Bassi P, Viale PL, Novati S, Ranieri S. Intestinal co-infection by Cyclospora sp. and Cryptosporidium parvum: first report in an AIDS patient. Parasite. 1994;1:387-90.

35. Maggi P, Brandonisio O, Larocca AM, Rollo M, Panaro MA, Marangi A, et al. Cyclospora in AIDS patients: not always an agent of diarrhoic syndrome. New Microbiol. 1995;18:73-6.

36. Masucci L, Graffeo R, Siciliano R, Franceschelli A, Bugli F, Fadda G. First Italian case of cyclosporiasis in an immunocompetent woman: local acquired infection. New Microbiol. 1995;31:281-4.

37. Giangaspero A, Marangi M, Arace E. Cyclospora cayetanensis travels in tap water on Italian trains. J Water Health. 2014;13:210-6.

38. Ortega YR, Sterling CR, Gilman RH. Cyclospora cayetanensis. Adv Parasitol. 1998:40:399-418.

\section{Submit your next manuscript to BioMed Central and take full advantage of:}

- Convenient online submission

- Thorough peer review

- No space constraints or color figure charges

- Immediate publication on acceptance

- Inclusion in PubMed, CAS, Scopus and Google Scholar

- Research which is freely available for redistribution 